\title{
A CODIFICAÇÃO DO CÓDIGO DE TRÂNSITO BRASILEIRO PARA O SISTEMA DE REPRESENTAÇÃO DE ULTRAPASSAGEM DE ACORDO COM A SEGUNDA TRICOTOMIA DA ANÁLISE SEMIÓTICA DE PEIRCE
}

\author{
Andreia de Bem MACHADO ${ }^{1}$ \\ José Onildo TRUPPEL FILHO \\ Richard Perassi Luiz de SOUSA ${ }^{3}$ \\ Luciana Dornbusch LOPES ${ }^{4}$
}

\begin{abstract}
${ }^{1}$ Doutoranda no Programa de Pós-Graduação em Engenharia e Gestão do Conhecimento (PPEGC) na Universidade Federal de Santa Catarina (UFSC). Mestre em Educação Científica e Tecnológica (PPGECT) na Universidade Federal de Santa Catarina (UFSC). Especialista em Alfabetização na Universidade do Estado de Santa Catarina (UDESC). Graduada em Pedagogia na Faculdade de Educação (FAED) na Universidade do Estado de Santa Catarina (UDESC) Experiência na área de Educação há mais de 20 anos e com ênfase em Educação a Distância (EaD) desde de 2004, atuando principalmente nos temas: material didático , orientação de trabalho de pós graduação a distância, planejamento, desenvolvimento, coordenação nos cursos a distância. As diferentes atividades desenvolvidas centram-se principalmente como Designer Instrucional (DI) e áreas pedagógicas relacionadas a EAD. Atualmente desenvolve trabalhos e pesquisas na área de Projeto, Metodologia e Design Instrucional para o planejamento, prática, acompanhamento e avaliação em $\mathrm{EaD}$, educação corporativa, inovação, parques tecnológicos bem como na área de Mídia e Conhecimento. andreiadebem@gmail.com
\end{abstract}

${ }^{2}$ Graduado em Direito (Univali). Especialista (Pós-graduação latu sensu) em Direito e gestão de trânsito (Cesusc) e em Administração de Segurança Pública (Unisul). Mestrando na área de Mídia e conhecimento do programa de Pós-graduação em Engenharia e Gestão do Conhecimento na Universidade Federal de Santa Catarina (PPG/EGC - UFSC). Major da PMSC e Professor da área de trânsito. jose.truppel@google.com

${ }^{3}$ Doutor em Comunicação e Semiótica pela Pontifícia Universidade Católica de São Paulo (2001), Mestre em Educação pela Universidade Federal de Mato Grosso do Sul (1995), Bacharel em Desenho de Propaganda e Licenciado em Artes Plásticas pelo curso de Educação Artística da Universidade Federal de Juiz de Fora (1986). Atualmente, atua como professor associado da Universidade Federal de Santa Catarina, nos cursos de graduação e pós-graduação em Design (PósDesign/UFSC) e no programa de Pós-Graduação em Engenharia e Gestão do Conhecimento (EGR/UFSC). Anteriormente, foi professor da Universidade Federal de Mato Grosso do Sul. Tem experiência nas áreas de Artes Visuais, Design, Comunicação, Semiótica e Educação, desenvolvendo os seguintes temas: Semiótica Visual, Arte, Design e Mídia, Identidade, Cultura e Comunicação das Marcas nas Organizações. É lider do grupo de pesquisa SIGMO/UFSC Significação da marca, informação e comunicação organizacional. richard.perassi@ ufsc.br

${ }^{4}$ Bacharela em Moda Habilitação Estilismo pela Universidade do Estado de Santa Catarina (2001); Especialista em Moda: Produção e Criação - UDESC (2004); Mestra pelo Programa de Pós-Graduação em Design e Expressão Gráfica (2012) do Centro de Comunicação e Expressão da UFSC, Linha de Pesquisa Hipermídia Aplicada ao Design Gráfico, ênfase em Hipermídias para Aprendizagem - Objetos de Aprendizagem para ensino virtual de Tecnologia do Vestuário. Doutoranda do Programa de Pós-Graduação em Engenharia e Gestão do Conhecimento ? PPGEGC, área de concentração Mídia e Conhecimento, com pesquisa em Objetos de Aprendizagem Hipermídia/MOOCs - Massive Open Online Courses A DISSEMINAÇÃO DO CONHECIMENTO DE MODA POR MEIO DA MÍDIA ?MOOC?: UM MODELO DE ENSINO INSTRUCIONAL AUTO-AVALIATIVO (2014). Atualmente é professora de nível superior 
da Universidade do Estado de Santa Catarina, no curso de Bacharelado em Moda no Centro de Artes CEART, com experiência na área de Artes, ênfase em MODA, atuando principalmente nos seguintes temas: Tecnologia do Vestuário: Modelagem; Ensino virtual de Tecnologia do Vestuário e Moda; Moda e Sustentabilidade; Coordena o Programa de Extensão - Modeline: Moda e Extensão Virtual da UDESC; é membro do Comitê de Ética para Pesquisa em Seres Humanos- CEPSH UDESC. d.lulopeslu@gmail.com

Recebido em: 26/09/2015 - Aprovado em: 10/01/2016 - Disponibilizado em: 30/07/2016

\title{
RESUMO
}

O Código de Trânsito Brasileiro (CTB), que regulamenta o trânsito, apresenta uma linguagem formal representada por símbolos, entre eles, as linhas das faixas no sistema de ultrapassagem. Este estudo tem como objetivo relacionar a codificação do CTB para o sistema de representação de ultrapassagem com a segunda tricotomia de análise semiótica da teoria de Charles Sanders Peirce, que avalia a relação entre o representâmen e oreferente/objeto. A segunda tricotomia apresenta três classificações do signo: ícone, índice e símbolo. Este estudo foi baseado nessa teoria por ser a semiótica a ciência que estuda todas as formas de linguagem.

Palavras-chave: Código de Trânsito Brasileiro. Linhas de ultrapassagem. Teoria semiótica de Peirce.Segunda tricotomia de Peirce.

\begin{abstract}
Brazilian Traffic Code regulates traffic in country andhas a formal language represented by lines in bands in the overdrive system. This study aim to relate the encoding of Brazilian Traffic Code to the overriding system of representation based on the second trichotomy of semiotic analysis of Charles Sanders Peirce theory (1839-1914). Peirce analyzes the relationship betweenrepresentamen andreferrer/object and his theory has three sign classifications: icon, index and symbol. We based this study in this theory because Semiotics is the science that analyzes all types of languages.
\end{abstract}

Keywords:Brazilian Traffic Code. Overtake lines. Peirce semiotic theory. Peirce second trichotomy.

\section{INTRODUÇÃOO}

A semiótica é uma área nova das Ciências Humanas e teve origem em três regiões: (1) vertente originada nos Estados Unidos; (2)vertente originada na antiga União Soviética; e (3)vertente originada na Europa Ocidental. Essa área de estudo tem como foco de análise a investigação de todos os tipos de linguagens existentes, seja oral, verbal, gestual, entre outras. Aorigem da denominação "semiótica" "vem da raiz grega semeion, que significa 'ciência dos signos', Semiótica é a Ciência dos signos" (SANTAELLA, 2005, p.1). Nesse contexto, o signo é entendido como linguagem verbal e nãoverbal.
A semiótica é a ciência que tem por objeto a investigação de todas as linguagens possíveis, ou seja, tem o intuito de examinar os modos de constituição de todo e qualquer fenômeno de produção de significação e de sentido (SANTAELLA, 2005, p.13). Os homens são mediados por uma rede de linguagem que proporciona nossa interação com o mundo e que dá orientação aos sinais, às imagens e aos gráficos disponibilizados no dia a dia. Entreos sinais que orientam os seres humanos, estão os sinais de trânsito.

No Brasil, os sinais de trânsito integram o Código de Trânsito Brasileiro (CTB) a fim de condicionar civilizadamente à atitude ética no trânsito, com base em regras convencionadas 
na forma de lei. Tais convenções são expressadas por intermédio de sinais e sinalizações percebidos pelos motoristas na condução dos veículos diversos sobre as vias de circulação. Os sinais e as sinalizações devem proporcionar a ação efetiva de direção segura para todos os envolvidos nesse contexto: veículos, motoristas, pedestres e animais.

Os sinais de trânsito fazem parte da vida cotidiana, especialmente nos meios urbanos, e do nosso mundo, portanto, entendê-los e respeitá-los, em se tratando do trânsito, é uma questão de sobrevivência. Ao se considerar dados de 2012 apenas, registraram-se 46.051 vítimas fatais no trânsito, segundo o Ministério da Saúde (DATASUS, 2012). Com a intenção de reduzir as vítimas no trânsito, principalmente aquelas decorrentes de colisões frontais,que apresentam maior possibilidade de morte, em 2014 foram agravadas as punições para as infrações de trânsito, reclassificando o valor da multa por ultrapassagem indevida pela contramão. Essa multa antes tinha o valor de $\mathrm{R} \$ 191,54$; a partir de $1^{\circ}$ de novembro de 2014 passou a valer $\mathrm{R} \$ 957,70$, ou seja, o valor foi multiplicado em cinco vezes.

Devido ao tema deste artigo,uma análise de parte doCTB, elegeu-se como objeto do estudo o subsistema de regulamentação de ultrapassagem, que compõe o sistema nacional de sinalização, mais especificamente o sistema de sinalização horizontal e a classificação das marcas longitudinais. A regulamentação de ultrapassagem possui vários aspectos a serem avaliados, como as determinações expressas na lei, as placas de sinalização, as pinturas sobre as pistas de trânsito e as linhas que regulam a ultrapassagem. Neste estudo, serão analisadas as marcas longitudinais, particularmente as representações gráficas visuais do sistema de regulamentação de ultrapassagem - linha de divisão de fluxos opostos (LFO) e linhade divisão de fluxos de mesmo sentido (LMS).Essas linhas indicam a intenção objetiva de regulamentar a ultrapassagem e, principalmente, de suscitar atitudes a serem tomadas pelos usuários das vias, por meio da interpretação das marcas pintadas, entre outras sinalizações, que comunicam significados às pessoas que circulam a pé e especialmente aos condutores dos veículos.

O significado que cada linha do sistema de representação de ultrapassagem tem na composição da sua linguagem pode ser analisado pela sua própriaimagem, pela sensação que ela proporciona, ou seja, pela representação simbólica.

A semiótica de Charles Sanders Peirce (18391914) definiu três categorias fenomenológicas para o estudo da experiência perceptivointerpretativa: (1) primeiridade, que se estabelece no campo das sensações e promove sentimentos; (2) secundidade, que promove um agente externo como causador da sensação;(3) terceiridade, que é a capacidade 
de interpretação que associa as duas categorias anteriores - qualidade e fato -, a partir do repertório vivencial e cultural do sujeito, sendo a capacidade que acessa o conhecimento (SOUSA, 2008, p. 25-26).

Peirceconsidera uma composição tríplice e classificatória para os signos dos fenômenos percebidos pela mente interpretadora, a qual é dada em relação a "sua qualidade, sua existência e seu caráter de lei” (SOUSA, 2008, p. 26).

A forma como o representâmen do signo estabelece a representação de seu objeto constitui a primeira tricotomia peirceana. $\mathrm{O}$ representâmen é o elemento percebido e faz alusão ao objeto:(1) pela sua qualidade (primeiridade),quando o objeto é classificado como quali-signo; (2) pela sua existência (secundidade), quando o objetoé classificado como sin-signo;(3) pelo seu caráter de lei (terceiridade), quando o objetoé classificado como um legi-signo (SOUSA, 2008, p. 26).

A maneira como o signo faz referência ao seu objeto estabelece a segunda tricotomia peirceana. Nesse caso, o signo é classificado como: (1) ícone, quando sugereo objeto por semelhança de sensações; (2) índice, quando sua existência é relacionada à existência do objeto; (3) símbolo, quando representao objeto pelo seu caráter de lei ou por convenção (PEIRCE, 2005).

A terceira tricotomia peirceana se estabelece com base na característica do interpretante produzida pelo signo. Desse modo, o signo pode ser classificado em: (1) rema, quando estabelece um interpretante por semelhança de sensações; (2) dicente, quando estabelece um interpretante por sua existência; argumento, quando estabelece um interpretante por seu caráter de lei ou convenção (SOUSA, 2008, p. 27).

Neste estudo, relacionou-se a codificação estabelecida no CTB para o sistema de representação de ultrapassagem com base na segunda tricotomia da análise semiótica de Peirce, que considera a maneira como o signo faz referência ao seu objeto de formaicônica, indicial e simbólica.

Este artigo está dividido em seis seções: esta primeira seção, introdutória; a segunda seção, que trata da descrição do objeto; a terceira seção, na qualapresentam-seas normas do CTB relacionadas às linhas e faixas do sistema de ultrapassagem; a quarta seção, que explicita a interpretação das linhas segundo a classificação de Pierce, na relação entre representâmen e referente; por fim, a quinta e sexta seções, nas quaisencontram-se, respectivamente, as considerações finaise as referências citadas ao longo deste estudo.

\section{DESCRIÇÃO DO OBJETO}

As imagens a serem descritas representam as formas das marcas longitudinais da sinalização horizontal do sistema de ultrapassagem do CTB, que são um conjunto de sinais gráficos da linguagem visual de trânsito, registrado sobre as vias de circulação 
pública. Para serem produzidos, tais sinais requerem materiais plásticos e tintas retrorrefletivas à noite para melhor visibilidade das marcas.

A linha simples contínua amarela (figura 1) são sinais representados geometricamente de forma retangular e direção linear sem interrupções de espaços, com duas dimensões: largura e comprimento. A área retangular da faixa de circulação é delimitada pela cor cinza, e a área retangular da linha é delimitada pela cor amarela. As faixas de circulação e a linha são dispostas paralelamente. As duas setas pretas apontam seus vértices para direções opostas.

Figura 1 - CTB: linha simples contínua amarela

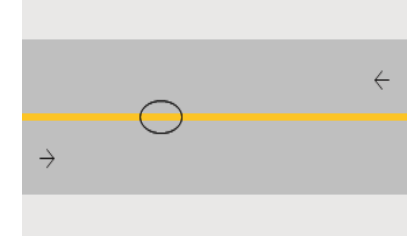

Fonte: Adaptado de Brasil, 2007, p. 11.

\section{A linha simples seccionada amarela (figura}

2) são sinais representados geometricamente de forma retangular e direção linear, com interrupções de espaços intercalados e sucessivos com comprimento maior do que os retângulos, com duas dimensões: largura e comprimento. A área retangular da faixa de circulação é delimitada pela cor cinza, e a área retangular dos traços da linha é delimitada pela cor amarela. As faixas de circulação e a linha são dispostas paralelamente. As duas setas pretas apontam seus vértices para direções opostas.
Figura 2 - CTB: linha simples seccionada amarela

Fonte: Adaptada de Brasil, 2007, p. 13.

A linha dupla contínua amarela (figura 3) são sinais representados geometricamente de forma retangular e direção linear sem interrupções de espaços, com duas dimensões: largura e comprimento. A área retangular da faixa de circulação é delimitada pela cor cinza, e as áreas retangulares das linhas são delimitadas pela cor amarela. As faixas de circulação e as linhas são dispostas paralelamente entre si. As duas setas pretas apontam seus vértices para direções opostas.

Figura 3 - CTB: linha dupla contínua amarela

Fonte: Adaptado de Brasil, 2007, p. 14.

\section{A linha contínua/seccionada amarela}

(figura 4) são sinais representados geometricamente por uma linha simples contínua amarela (figura 1) e uma linha simples seccionada amarela (figura 2), dispostas paralelamente entre si.

Figura 4 - CTB: linha contínua/seccionada amarela

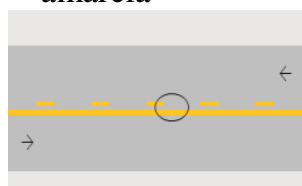

Fonte: Adaptado de Brasil, 2007, p. 13.

A linha simples contínua branca (figura 5)

são sinais representados geometricamente de forma retangular e direção linear sem interrupções de espaços, com duas dimensões: largura e comprimento. A área retangular da 
faixa de circulação é delimitada pela cor cinza, e a área retangular da linha é delimitada pela cor branca. As laterais das áreas das faixas de circulação também são delimitadas pela linha simples contínua branca. As faixas de circulação e as linhas são dispostas paralelamente. As duas setas pretas apontam seus vértices para mesma direção.

Figura 5-CTB: linha simples contínua branca

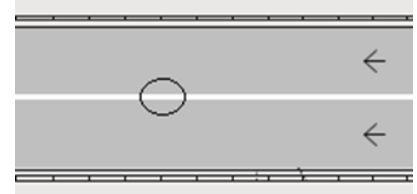

Fonte: Adaptado de Brasil, 2007, p. 22.

A linha simples seccionada branca(figura 6) são sinais representados geometricamente de forma retangular e direção linear, com interrupções de espaços intercalados e sucessivos com comprimento maior do que os retângulos dos traços, com duas dimensões: largura e comprimento. A área retangular das faixas de circulação (figura 6) é delimitada pela cor cinza, e as áreas retangulares dos traços da linha são delimitadas pela cor branca. As faixas de circulação e as linhas são dispostas paralelamente. Cada par de setas pretas aponta seus vértices para mesmas direções, e um par em relação ao outro aponta seu vértice para a direção oposta.

Figura 6-CTB: linha simples seccionada branca

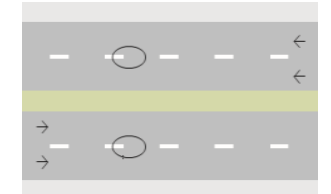

Fonte: Adaptado de Brasil, 2007, p. 24.

\section{A SIGNIFICAÇÃO DAS LINHAS SEGUNDO TRICOTOMIA DE PEIRCE}

$\mathrm{Na}$ tríade de composição do signo da teoria semiótica de Charles Sanders Peirce (representâmen, objeto, interpretante), o conceito de ultrapassagem do CTB, de essência abstrata, é o objeto ou referente e se configura graficamente como um conjunto de sinalizações horizontais definidas como marcas longitudinais, que são percebidas visualmente como uma composição de linhas planificadas. O objeto "ultrapassagem" é composto por seis tipos de linhas que o representam, fazendo a função de signo ou representâmen, das quais seis foram descritos na seção 2 deste estudo, com base em imagens de caráter desenhístico (GOMES, 1996, p. 21).

Essas linhas se dispõem da forma estabelecidano CTB por longos segmentos sobre as vias rurais e urbanas de circulação, compondo um conjunto visual no qual, estruturalmente, as vias são objetos produzidos em três dimensões: largura, comprimento e altura.Entretanto, considerando a superfície visual, as vias são objetos planos que perpassam os contextos naturais e urbanos, indicando percursos de condução predominantemente lineares que, por vezes, se dispõem linearmente sinuosos, tanto as vias e, respectiva e adjacentemente, as linhas, dependendo das características 
geográficas, geológicas, ambientais, naturais e culturais, em se tratando das vias nas cidades. Pelo aspecto linear em longos segmentos, as linhas (signos) de ultrapassagem (objeto abstrato), designadas na lei como marcas longitudinais, são demarcações lineares no sentido do comprimento e dispõem-se, ainda, de forma paralela. Isso fornece ao signo, junto das formas linear e plana, um atributo visual no qual se evidenciam retas que apresentam, em suas extremidades no sentido da largura, ângulos de $90^{\circ}$ pelo encontro perpendicular dessas retas, resultando numa figura geométrica de área retangular. Culturalmente se estabeleceu o entendimento de que as formas retas, paralelas, angulares e planas, tanto para representações em duas quanto em três dimensões, remetem às ideias de ordem e organização, possibilitando uma leitura simples e clara do objeto e tendendo a expressar mais o conceito de objeto estático do que de objeto dinâmico (TEIXEIRA; MATOS; SOUSA, 2011). As linhas retas e paralelas fazem relação de harmonia com as vias pela composição formal de sobreposição e oferecem regularidade pelo alinhamento dos elementos,constituindo uma linguagem formal e condicionando o usuário a movimentos retilíneos. Trata-se de uma composição visual que diverge das formas orgânicas, próprias da natureza e que são associadas mais a objetos dinâmicos. Um objeto que estruturalmente se mostra plano e geométrico por alinhamentos linearmente paralelos designa as sensações de ordem e delimitação de espaços trafegáveis, e sua longitude designa as sensações de direcionamento e mobilidade (GOMES FILHO, 2003).

As imagens das linhas do sistema de ultrapassagem descritas não apresentam sinuosidades, entretanto, por se tratarem de uma unidade mínima de representação do todo dos trajetos longos das vias rurais e urbanas, as linhas podem percorrer no contexto da realidade, por vezes, espaços com direções curvilíneas, que são designados pela lei de traçado geométrico vertical ou horizontal irregular - curvas acentuadas, em que haverá a presença de sinalização horizontal, entre outras situações, indicando a proibição ou a permissão da ultrapassagem, conforme haja distância mínima de visibilidade. A condição de curva da via não altera a forma de apresentação das linhas, que continuam a remeter às ideias de ordem e delimitação pela sua configuração retilínea, angular, paralela e plana. Porém, ao contrário do conceito culturalmente estabelecido de que as formas orgânicas, de configurações sinuosas, são associadas a objetos dinâmicos, a condição curvilínea das vias influencia de maneira menos dinâmica a condução dos veículos do que nas vias retas, por leis da física e por proporcionarem menor visibilidade do trânsito.

As imagens de natureza desenhada deste estudo (representâmen) têm caráter icônico e 
representam as linhas do sistema de ultrapassagem fazendo relação, com o objeto ou referente, de semelhança na aparência das formas e cores das linhas marcadas nas vias. O signo faz também relação icônica com o objeto, levando a associações das formas retangulares com obstáculos materiais, como os muros, que, apesar de serem objetos construídos fisicamente em três dimensões, demarcam espaços com finalidades diversas, organizando socialmente a convivência, por limitarem o acesso a suas áreas a quem seja permitido. Há variação icônica entre as faixas que ora apresentam linhas amarelas, ora linhas brancas de separação entre as faixas. As linhas amarelas devem incitar maior estímulo sensorial nos usuários na condução dos veículos, pois informam simbolicamente a ordenação de sentidos opostos de fluxo de movimentos veiculares e, ao não serem interpretadas corretamente,pode haver maior risco de acidentes graves. As linhas brancas devem incitar menor estímulo sensorial nos usuários, pois informam simbolicamente a ordenação de fluxo de movimentos veiculares de mesmo sentido, o que supostamente proporciona menor risco de acidentes graves. As faixas separadas pelas linhas amarelas propiciam menor autonomia de ação, e as faixas separadas pelas linhas brancas oferecem maior autonomia de ação. Há, ainda, variação icônica na forma das linhas ao se apresentarem contínuas, proibindo simbolicamente a ultrapassagem, e/ou ao se apresentarem seccionadas, permitindo simbolicamente a ultrapassagem.

A imagem da linha que se forma na mente do observador a partir do ícone desenhístico é percebida como signo indicial de direção vertical ou horizontal, norte, sul, leste, oeste, que aponta por onde se deve trafegar e quais os sentidos de tráfego são permitidos na direção determinada.

A pista e a linha em seu eixo central de rolamento tratam-se, ainda, de uma composição percebida como signo indicial de demarcação de um espaço em relação a outros subjacentes. Considerando que o desenho foi elaborado utilizando tinta, as linhas de trânsito traçadas no asfalto são um índice de tinta.

O signo - linhas viárias de ultrapassagem relaciona-se ao objeto pelo seu caráter de lei e por convenção, portanto,é também um signo simbólico devido às convenções culturais e significativas das linhas de trânsito.A rigorosa apresentação formal icônica (que leva às sensações de ordem, delimitação, direcionamento e mobilidade) e sua condição existente indicial (que leva às associações com obstáculos físicos e demarcações físicas, considerados em conjunto com as regras codificadas de proibição e permissão de ultrapassagem) geram interpretantes na mente de todo usuário, o que no âmbito da terceiridade se denomina como organização, regulamentação e segurança. 


\section{CONSIDERAÇÕES FINAIS}

A representação acompanha o ser humano desde os primórdios, pois sempre houve uma preocupação em se comunicar através de gestos, linguagens, símbolos e signos.

As formas do sistema de ultrapassagem,que são desenhadas por linhas e que determinam as ações ocorridas no trânsito, são reguladas pelo CTB.

Com base na segunda tricotomia de análise de Peirce, a relação do CTB para o sistema de representação de ultrapassagem contém signos icônicos, indiciais e simbólicos que representam umcódigo de regras de circulação determinado pelo ser humano para impor ordem, direção, mobilidade e segurança no trânsito.

Ao se declarar consensualmente que as imagens do sistema de ultrapassagem do CTB simbolizam organização, regulamentação e segurança, admite-se que as linhas do sistema real permitem o cumprimento da ação ética de mobilidade no trânsito na mediação entre atenção e ultrapassagem, requeridas em situações trafegáveis em vias rurais e urbanas de trânsito, as quais implicam uma condição de segurança para a ação efetiva de conduzir automóveis no sistema viário de circulação.

\section{REFERÊNCIAS}

BRASIL. Lei ${ }^{\circ}$ 9.503, de 23 de setembro de 1997. Institui o Código de Trânsito

Brasileiro. Brasília, 1997. Disponível em:
<http://www.planalto.gov.br/ccivil_03/Leis/L 9503.htm>. Acesso em:15 dez. 2014.

CONSELHO NACIONAL DE TRÂNSITO.

Resolução n ${ }^{\circ}$ 236, de 11 de maio de 2007. Aprova o Manual Brasileiro de Sinalização Horizontal.Brasília, 2007. Disponível em: $<$ http://www.denatran.gov.br/download/Resol ucoes/RESOLUCAO_CONTRAN_236.pdf>. Acesso em:15 dez. 2014.

\section{Manual de sinalização horizontal.}

1. ed. Brasília: Contran, 2007. (Manual Brasileiro de Sinalização de Trânsito; 4).

Disponível em:

<http://www.denatran.gov.br/publicacoes/do wnload/manual_horizontal_resolucao_236.pd f>. Acesso em:5 jan. 2015.

DATASUS. Mortalidade Brasil: 2012.

Disponível

em: <http://tabnet.datasus.gov.br/cgi/tabcgi.ex e? sim/cnv/obt10uf.def $>$. Acesso em: $15 \mathrm{dez}$. 2014.

FARIA, E. de O. História dos transportes terrestres no mundo. Disponível em: $<$ http://www.transitocomvida.ufrj.br/Histo riaDoTransitoNoMundo.asp $>$. Acesso em: 8 jan. 2014.

GOMES FILHO, J.Gestalt do objeto: sistema de leitura visual da forma. 5.ed. São Paulo: Escrituras, 2003.

GOMES, L. V. N. Desenhismo. 2. ed. Santa Maria: UFSM, 1996. 120 p.

JAPIASSU, H.; MARCONDES, D.Dicionário básico de filosofia. 4. ed. Rio deJaneiro: Zahar, 2001.

PEIRCE, C. S. Semiótica. São Paulo: Perspectiva, 2005.

RIZZARDO, A.Comentários ao Código de Trânsito Brasileiro. 7. ed. São Paulo: Revista dos Tribunais, 2008.

SANTAELLA, L.O que é semiótica. São Paulo: Brasiliense, 2003. (Primeiros Passos).

SOUSA, R. P. L.de. Semiótica: texto didático. Universidade Federal de Santa 
Catarina - UFSC. Centro de Comunicação e Expressão, Departamento de Expressão

Gráfica, Curso de Design. Apostila de PósGraduação. Florianópolis, 2008.

TEIXEIRA, J. M.; MATOS, L. M.; SOUSA, R. L. P. de. Análise semiótica da imagem de uma cadeira. Estudos Semióticos, v. 7, n. 2, São Paulo, 2011, p. 102-109. Disponível em: <http://www.fflch.usp.br/dl/semiotica/es/eSSe 72/2011esse72_jmteixeira_lmmatos_rperassi. pdf>. Acesso em: 6 jan. 2015.

TRUPPEL FILHO, J. O. Sistema Nacional de Trânsito. Palhoça: UnisulVirtual, 2011. 